\title{
Des migrants subsahariens dans les champs de Coco de Paimpol en Bretagne, entre camaraderie et clivages
}

Ibrahima Diallo

\section{(2) OpenEdition \\ Journals}

Édition électronique

URL : https://journals.openedition.org/itti/2059

DOI : 10.4000/itti.2059

\section{Éditeur}

Université de Poitiers

\section{Référence électronique}

Ibrahima Diallo, « Des migrants subsahariens dans les champs de Coco de Paimpol en Bretagne, entre camaraderie et clivages », Images du travail, travail des images [En ligne], 11 | 2021, mis en ligne le 01 septembre 2021, consulté le 18 février 2022. URL : http://journals.openedition.org/itti/2059 ; DOI : https://doi.org/10.4000/itti.2059

Ce document a été généré automatiquement le 18 février 2022.

Images du travail, travail des images 


\section{Des migrants subsahariens dans les champs de Coco de Paimpol en Bretagne, entre camaraderie et clivages}

Ibrahima Diallo

Des migrants subsahariens dans les champs de Coco de Paimpol en Bretagne

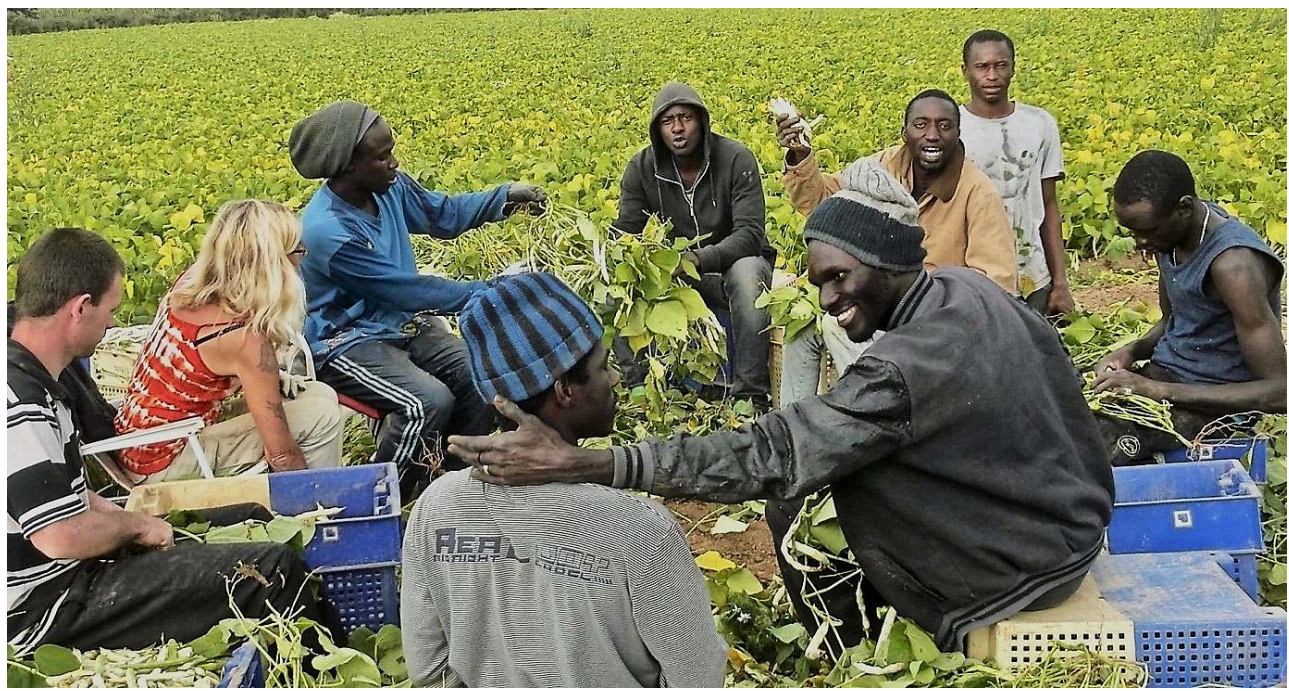

Cette photographie a été prise en septembre 2014, lors d'une enquête ethnographique dans les champs de haricots coco à Paimpol (Bretagne), au moment de la récolte. Ma recherche portait alors sur les migrants subsahariens qui effectuent des travaux agricoles saisonniers dans diverses régions de France. L'auteur de ce texte apparaît sur la photo (debout, au fond, en tee-shirt blanc). C'est un camarade saisonnier qui a pris le cliché1. 
2 On y voit, au milieu d'une équipe d'individus à la peau noire, deux individus à la peau blanche : une femme et un jeune homme, à gauche sur la photo. La plupart de ces individus sont assis sur des caisses vides ou des chaises. Ils finissent de travailler : ils ont encore des plants de cocos sur les genoux et ils ont l'air joyeux. Au premier plan de la photographie, l'un d'entre eux prend un de ses compagnons par le cou. Ce geste témoigne de la camaraderie et de la fraternité qui lient les saisonniers. Au second plan, trois jeunes hommes semblent regarder en direction du photographe, dont l'auteur du texte. Ils semblent demander au photographe de prendre non seulement une belle photo mais, surtout, de réaliser une image qui montre tous les saisonniers; le premier cliché était un peu flou et ne montrait que quelques saisonniers. L'un des trois montre les gousses de cocos qu'il tient dans sa main.

3 Le ramassage des cocos se fait en effet à la main. Chaque saisonnier prend des plants mûrs dans le tas qu'il a formé en les arrachant, il en sépare les gousses et les dépose dans une caisse. Pendant le travail, les cueilleurs portent généralement des gants, car la cueillette des gousses de cocos peut blesser aux mains et entraîner des boursouflures. Un ramasseur regroupe les caisses pleines, qui pèsent entre vingt et vingt-cinq kilos et les posent les unes sur les autres. Erwan, l'exploitant du champ, passe trois fois dans la journée avec son tracteur et sa remorque : à onze, quatorze et dix-sept heures. Il s'arrête à hauteur des saisonniers, là où les caisses ont été regroupées, pour les peser sur une balance électronique. Puis, il charge les caisses sur la remorque et les livre à la coopérative à laquelle il est affilié.

4 Chaque saisonnier est payé au poids cueilli : sa rémunération dépend donc de sa capacité à remplir le plus de caisses possibles. Il met entre une et deux heures pour remplir une caisse, selon son rythme de travail.

5 Sur cette photographie apparaissent deux groupes de travailleurs agricoles saisonniers : les « anciens » et les " nouveaux venus ». Les premiers sont généralement des autochtones (retraités, jeunes, hommes ou femmes qui habitent aux alentours), comme les deux individus à la peau claire assis à gauche sur l'image. Ils travaillent dans les zones les plus rentables, où les plants portent le plus de cocos et qui permettent donc de remplir leurs caisses le plus rapidement. Les seconds, des migrants subsahariens pour la plupart, sont cantonnés dans les zones périphériques du champ, moins rentables. Les individus du groupe à la peau foncée - dont l'auteur de ces lignes fait partie - avaient été affectés à une zone périphérique mais, après avoir récolté l'ensemble des cocos de la zone, ils ont rejoint les membres du premier groupe pour les aider à terminer leur récolte. Il s'agit des deux cueilleurs à la peau blanche, Anne et son fils, et de Mass, le mari d'Anne, l'homme à la peau noire assis à côté d'elle. Cette entraide gratuite, ce " coup de main » donné, est une manière pour les saisonniers de remercier Anne qui les a recrutés. Erwan confie en effet à Anne le recrutement de sa main-d'œuvre supplémentaire pendant la période du pic de production, à partir du 15 août.

6 Les cueilleurs ne forment donc pas un groupe homogène. Ils sont non seulement divisés entre "anciens" et "nouveaux venus" mais aussi entre autochtones et nonautochtones, entre «Blancs» et « Noirs». Si les uns et les autres ne sont pas affectés aux mêmes zones dans les champs, des passerelles existent de l'un à l'autre, comme c'est le cas pour Mass et Anne, en raison du lien conjugal qui les unit et qui a permis à Mass - du fait de son expérience - de basculer dans le premier groupe. 
7 Sur le cliché, la journée de travail est pratiquement terminée. Les cueilleurs ont retiré leurs gants, ils plaisantent. Deux d'entre eux se sont lancé un défi : lequel est le plus fort à la lutte sénégalaise ? C'est celui au premier plan, avec son bonnet bleu à rayures noires qui a été déclaré vainqueur. Il est félicité par son camarade qui le prend par le cou!

\section{NOTES}

1. La photo est libre de droit.

\section{AUTEUR}

\section{IBRAHIMA DIALLO}

Docteur en sociologie et ingénieur de recherche au Centre Émile Durkheim, Université de Bordeaux. 